\title{
The Impact of Climate Change on Agricultural and Livestock Production and Groundwater Characteristics in Abu Dhabi, UAE
}

\author{
L. S. Al Blooshi*†, T. S. Ksiksi*, M. Aboelenein** and A. S. Gargoum*** \\ *Biology Department, UAE University, Al-Ain, UAE \\ **Sociology Department, UAE University, Al-Ain, UAE \\ ***Statistics Department, UAE University, Al-Ain, UAE \\ $†$ Corresponding author: Latifa Saeed Al Blooshi; 200670339@uaeu.ac.ae
}

Nat. Env. \& Poll. Tech.

Website: www.neptjournal.com

Received: 03-02-2020

Revised: $10-03-2020$

Accepted: 02-05-2020

Key Words:

Agriculture

Climate change

Groundwater

Irrigation

\begin{abstract}
Agriculture is located at the crossing point between ecosystems and society, where changes in the global environmental conditions affect agricultural activities. The total agricultural area in Abu Dhabi Emirate in 2017 was 749,868 donums. This study had two main objectives; first, to understand how agricultural and livestock production has changed and how these changes are relevant to socioeconomic statuses; second, to assess climate change's impact on agricultural and livestock production through groundwater characteristics. We distributed and collected 301 surveys throughout the three main regions in the Abu Dhabi Emirate (Abu Dhabi City, Al-Ain City, and Al Dhafrah). The results indicated that approximately $68 \%$ of the respondents in Al-Ain agreed that it is currently much easier and more profitable to manage a farm than it was 20 years ago. Further, 39\% of the farmers agreed that both product quality and quantity have improved over the past 20 years. About $51 \%$ of Emirati nationals agreed that production has changed over time. The farmers aged between 51-60 years also agreed that there has been a change in production over time. Half of the farm owners agreed that production has changed, while a majority of the workers provided neutral responses on this topic. While a number of both owners and workers agreed that both production and income levels changed, more respondents disagreed than agreed that these changes had occurred. Finally, the farmers aged between 51-60 years agreed more that the groundwater levels and quality had changed over the past 20 years.
\end{abstract}

\section{INTRODUCTION}

Agriculture is located at the crossing point between ecosystems and society (Olesen \& Bindi 2002). Changes in the global environmental conditions affect agricultural activities, but these activities contribute nearly $20 \%$ of the greenhouse gas emissions (methane and nitrous oxide in particular) (Rosenzweig \& Hillel 2000). Climate is the main determinant of agricultural productivity, and agriculture's processes of food and fibre production heavily burden the environment (Ibrahim et al. 2015). It is expected that climate change will affect agriculture in various ways across the globe (Parry et al. 1999). These effects are highly dependent on the current climatic and soil conditions, the pathways of change, and a region's ability (based on infrastructure and resources) to survive the change (Olesen \& Bindi 2002). Based on Stocker et al. (2013) Summary for Policymakers in an Intergovernmental Panel on Climate Change Report, anthropogenic influences have been altering the global water cycle since 1960. Anthropogenic influences have magnified moisture content in the atmosphere, which led to global-level changes in the precipitation patterns over land. Currently, cultivated ecosystems have replaced natural vegetation in many areas of the world to grow crops. Unfortunately, many of these cultivated areas have been abandoned for cultural, economic and sustainability reasons (McGuire et al. 2001).

Past experiments have demonstrated that increasing temperatures will generally be beneficial for many fieldgrown vegetable crops, as this crop production can continue to expand northwards. Temperature increases in certain areas will allow for longer harvesting seasons, leading to continuous market supplies for longer periods throughout the year (Olesen \& Bindi 2002). According to the Statistics Centre Abu Dhabi (SCAD)'s 2018 yearbook, horticultural crops covered approximately 5,118 donums of the total cultivated areas in Abu Dhabi Emirate in 2017 (SCAD 2018). The main effects of climatic warming, that is projected for the protected crops, would be changes in the greenhouses' heating and cooling requirements (Olesen \& Bindi 2002). As time passes, scientists are becoming more confident that an increase in greenhouse gases will lead to a rise in global temperatures (Houghton et al. 1996). Developing countries have thus become more concerned about climate change's 
economic impact on agriculture (Watson et al. 1996). Developing countries largely rely on climate-dependent agriculture; this dependence, in conjunction with poverty rates and rapid population growth, makes developing countries highly vulnerable to climate change (Porter et al. 2014).

Climate change will influence crop and livestock production, hydrologic balances, and several other agricultural system components. Nevertheless, the human responses to these biophysical effects are complex and undefined (Ibrahim et al. 2015, Al-Maamary et al. 2017). Livestock production, like any other production process, releases carbon gases as a result of the energy and fertilizer used in the production process. Cultivated soil, land-use change, and the animals themselves can also release carbon gases (Steinfeld et al. 2006, Gerber et al. 2010). The Ministry of Economy (MOE) reported that the amount of rainfall in the northern and eastern parts of the United Arab Emirates UAE increased from $31 \mathrm{~mm}$ in 2001 to $145.5 \mathrm{~mm}$ in 2006 (MOE 2007). For these regions, heavy rainfall periods may occur every 10 years (Rizk et al. 1997). In the Arab Gulf states, there is still a dilemma about specifying the water stress levels. However, both virtual water trading and desalination can lessen the many surrounding water stress issues that might occur (Al-Maamary et al. 2017).

The majority of studies have only focused on the local impacts of climate change on the rainfall that feeds agriculture (Al Shidi et al. 2016). However, climate change's impacts on human societies will vary according to numerous factors, such as the amount of low-lying or arid land they inhabit and/or their degree of dependence on agriculture or aquatic resources (Bruce et al. 1996). Water vitally links climate change and agriculture. Water is the base upon which agriculture rests, yet climate change induced temperatures are expected to cause a wider variability in rainfall and temperatures (Sanderson \& Curtis 2016).

In the UAE, there has been both a reduction in groundwater resources and an increase in demand for water, leading to stressful situations and limited natural water resources (Murad 2010). Groundwater aquifers depend on precipitation, and precipitation is then highly dependent on the climate. Groundwater is the main freshwater source in the Arabian Gulf Countries' hydrological cycles, and this source (especially during droughts) provides water for daily human consumption, agriculture, industry, and other sectors (Kløve et al. 2014). Based on the above information, this study's research questions are the following: (1) Have agricultural and livestock production changed over the past 20 years in UAE? (2) Has climate change influenced the agricultural and livestock production in UAE? The research objectives of this study are twofold. First, this study aims to understand how agricultural and livestock production has changed and how these changes are relevant to socioeconomic statuses. Second, this study attempts to assess climate change's impact on agricultural and livestock production by analysing groundwater characteristics.

\section{STUDY AREA}

Abu Dhabi is the capital and the largest UAE emirate by area $\left(67,340 \mathrm{~km}^{2}\right)$, accounting for approximately $87 \%$ of the country's total land area (excluding islands). This Emirate's topography is dominated by a low-lying sandy terrain dotted with sand dunes, many of which exceed 300 meters in height in certain southern areas. Eastern Abu Dhabi borders the western fringes of the Al-Hajar Mountains. The mountain with the highest elevation in Abu Dhabi is Hafeet Mountain, which is located south of Al-Ain city and reaches approximately 1,300 meters in height. The emirate is located in the tropical dry region. The climate is arid, and the region experiences high temperatures throughout the year with very hot summers. Abu Dhabi has warm winters and only occasionally experiences low temperatures. There are variations in air temperatures among the coastal strip in Abu Dhabi City, the desert interior in Al Dhafra and Al-Ain City, and the areas of higher elevation. These areas together comprise the Emirate's topography. The total agricultural area in Abu Dhabi Emirate in 2017 was 749,868 donums. Al-Ain City had the largest area of plant holdings with approximately 452.503 donums, Al Dhafra had the secondlargest area with 207.686 donums, and Abu Dhabi had the third-largest area with 89.679 donums. Based on the SCAD's 2018 statistical yearbook, the total amount of field crop production in 2017 was 234,230 tons, with 16,381 tons in the Abu Dhabi region, 163,056 tons in the Al-Ain Region, and 54,793 tons in the AlDhafra Region.

\section{DATA AND METHODOLOGY}

Fig. 1 displays the content and coverage area included in the study's survey. The survey content includes general information, production, costs, and income.

The survey includes 38 questions that are grouped into three sections, questionnaires A, B, and C (see Appendix 1). Table 1 shows the categories and questions that are included in each questionnaire. Many survey questions (Q1, Q2, Q3, Q6...) are relevant to more than one category (production and cost of production and income).

We applied a principal component analysis (PCA) to convert the possibly correlated variables into a set of values of linearly uncorrelated variables. However, this analysis did not show a realistic connection between the variables within the set of values. We performed a pilot study to assure that the questions were clear and answerable. We received feed- 


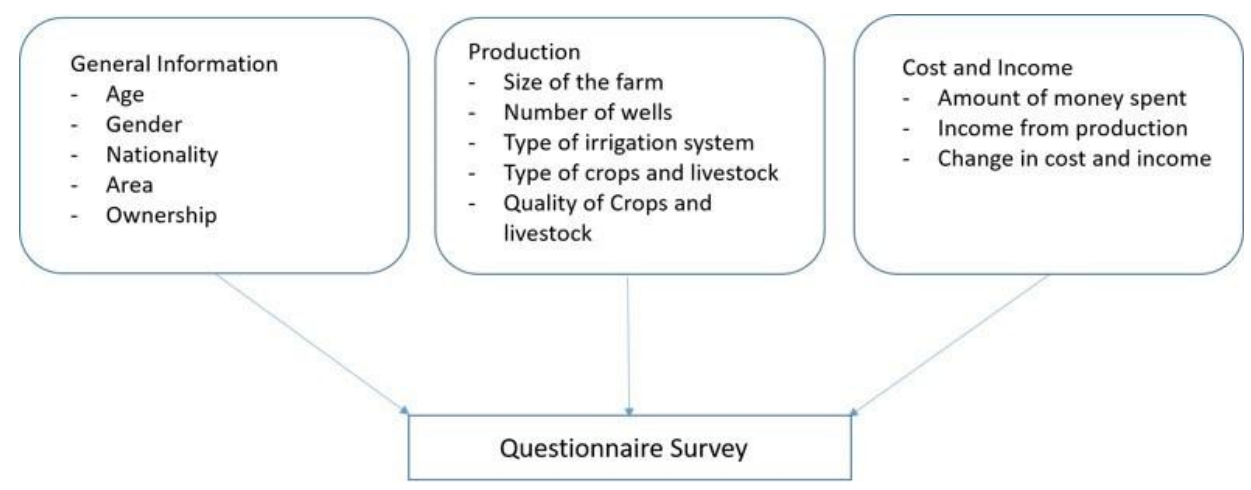

Fig. 1: Survey content and coverage areas.

Table 1: Questionnaire categories and survey questions.

\begin{tabular}{|ll|}
\hline Category & Survey questions \\
\hline Production (quantity and quality) & Q1, Q2, Q6 to Q19, Q24, Q29, Q32, Q34, Q35, Q37, Q38 \\
Wells and groundwater & Q4, Q5, Q23, Q24, Q25, Q26 \\
Income and cost of production & Q1 to Q3, Q6 to Q22, Q24, Q28, Q30, Q31, Q33, Q36-Q38 \\
Change in production over time & Q20, Q26, Q27, Q28, Q30 to Q36 \\
\hline
\end{tabular}

back from a volunteer who is a colleague that owns a farm, and the survey was modified accordingly. We collected 301 questionnaires in the three cities of the study area.

We distributed the questionnaires according to the regions' production percentages. We used descriptive statistical methods, and used nonparametric tests to compare the quantitative data at different levels of the sociodemographic variables.

\section{RESULTS}

Of the 301 collected surveys, 300 of the respondents were male and one was female. The respondents included 162 Emiratis who own farms, 19 Arabs who work on farms, and 1120 Asians who also work on farms. We collected 171 surveys in Al-Ain, 80 in Al Dhafrah, and 50 in Abu Dhabi. Approximately $50 \%$ of the respondents were aged between 31 to 40 years old. Fig. 2 displays the pie charts that represent the survey's demographic and general information. We conducted a Cronbach's Alpha reliability test to measure the internal consistency of the questionnaire groupings. The results indicate that the Cronbach's Alpha values were more than $80 \%$ for questionnaires B and C, while it was $56 \%$ for Questionnaire A. The acceptable values are more than 70\% yet for Questionnaire A, the questions are general and will not affect the results. These results might have occurred because the questions are nominal, but we still consider our data to be reliable (Table 2). The survey includes five farm sizes, ranging between $10,000 \mathrm{sqft}$ as small size farms to the big size farms, which are more than 1,000,000 sqft. Above $80 \%$ of the farms in Al-Ain are larger than 1,000,000 sqft. In $\mathrm{Al}$ Dhafrah, $60 \%$ of the farms are between 10,000 to $50,000 \mathrm{sqft}$ in size, while $22 \%$ of the farms in Abu Dhabi are between 55,000 to $100,000 \mathrm{sq} f t$ in size.

Nearly $60 \%$ of the farmers in Al-Ain use sprinklers for their irrigation systems, followed by the Aflaj irrigation system (an old irrigation system used mainly for date palm planting) and the drip system. The majority of Abu Dhabi farmers use drip as irrigation system (25\%), while 34\% of farmers use the Aflaj system in Al Dhafrah.

Cows comprise the largest number of livestock in Al-Ain (67\%). In AI Dhafrah and Abu Dhabi, the largest number of livestock are camels (31\%) and goats (24\%), respectively. Fig. 3. Since the category for other is undefined, we excluded this category from the analysis. Approximately $68 \%$ of the respondents in Al-Ain agreed that managing a farm nowadays is much easier and more profitable than it was 20 years ago. In Al Dhafrah, 29\% of the respondents agreed with the profitability statement, while the majority of the Abu Dhabi respondents disagreed.

Table 2: Cronbach's Alpha values for each questionnaire group.

\begin{tabular}{|ll|}
\hline Questionnaire & Cronbach's Alpha \\
\hline Questionnaire A & 0.562 \\
Questionnaire B & 0.913 \\
Questionnaire C & 0.835 \\
\hline
\end{tabular}




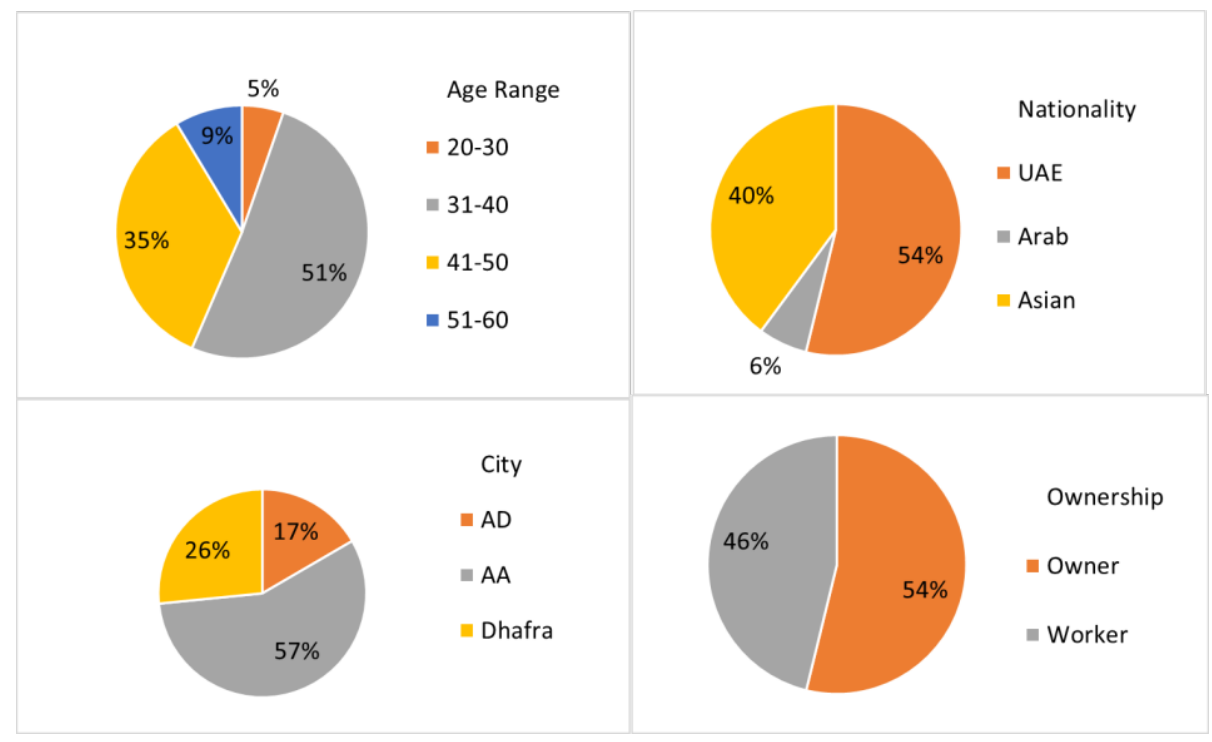

Fig. 2: Demographic and general information collected from the survey.

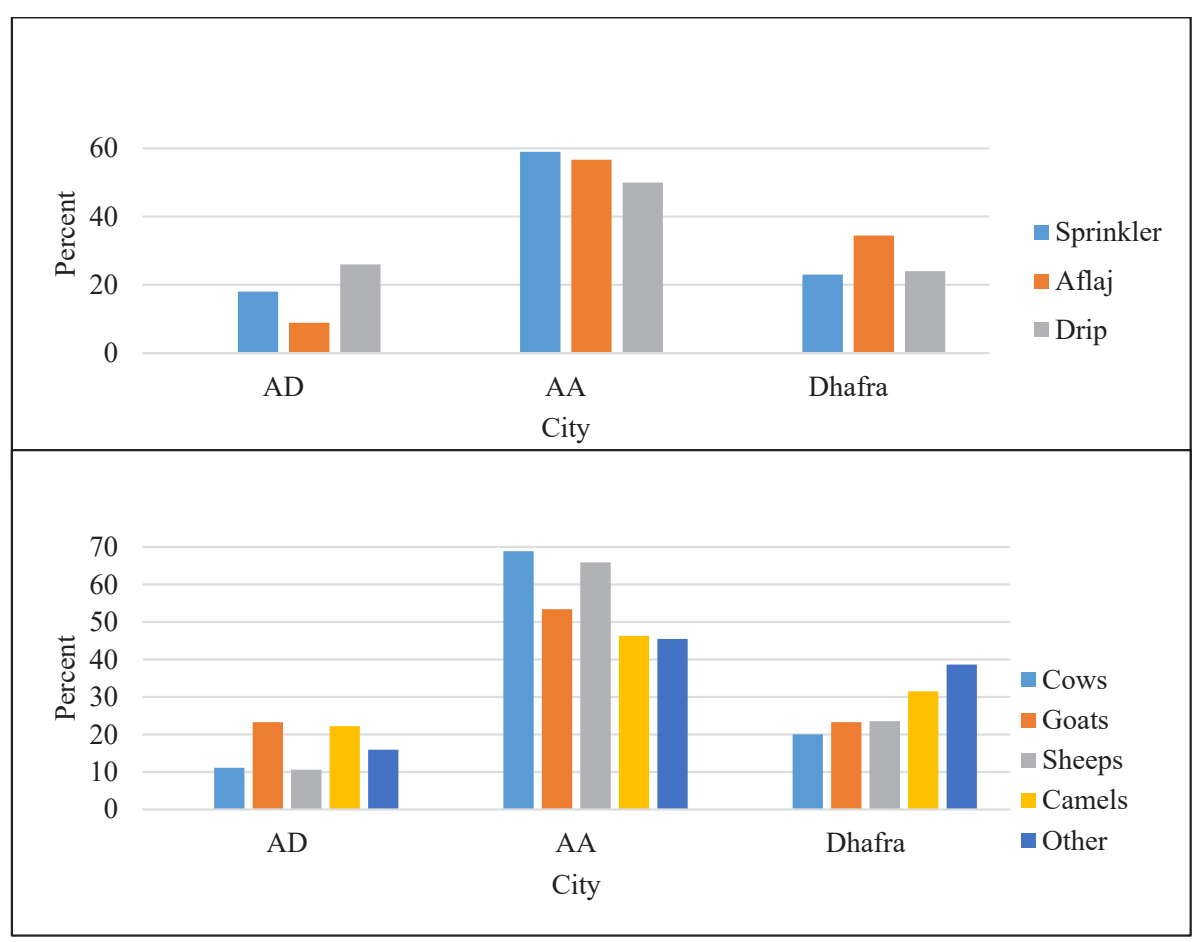

Fig. 3: Irrigation systems and livestock production.

In regard to the question that gauged whether farmers spent more money raising livestock over the past 20 years, the majority (60\%) of Al-Ain respondents either disagreed or responded neutrally. Nearly $70 \%$ of the respondents in Abu Dhabi, and $34 \%$ of the respondents in AI Dhafrah, disagreed that raising livestock has been more expensive. More than
$50 \%$ of the farm owners (UAE nationals) strongly agreed that their crop sales have increased over the past 20 years, while the majority of workers (Arabs and Asians) either disagreed or responded neutrally (Fig. 4). Approximately $65 \%$ of the farmers living in Al-Ain strongly agreed that the groundwater's salinity has increased over the past 20 
years. In AI Dhafrah, $28 \%$ of the farmers agreed with the groundwater salinity statement, while $24 \%$ of the respondents in Abu Dhabi disagreed. The respondents in Abu Dhabi and
AlDhafrah strongly disagreed that the depth of groundwater in the wells has decreased over the past 20 years, while $73 \%$ of the farmers in Al-Ain strongly agreed.

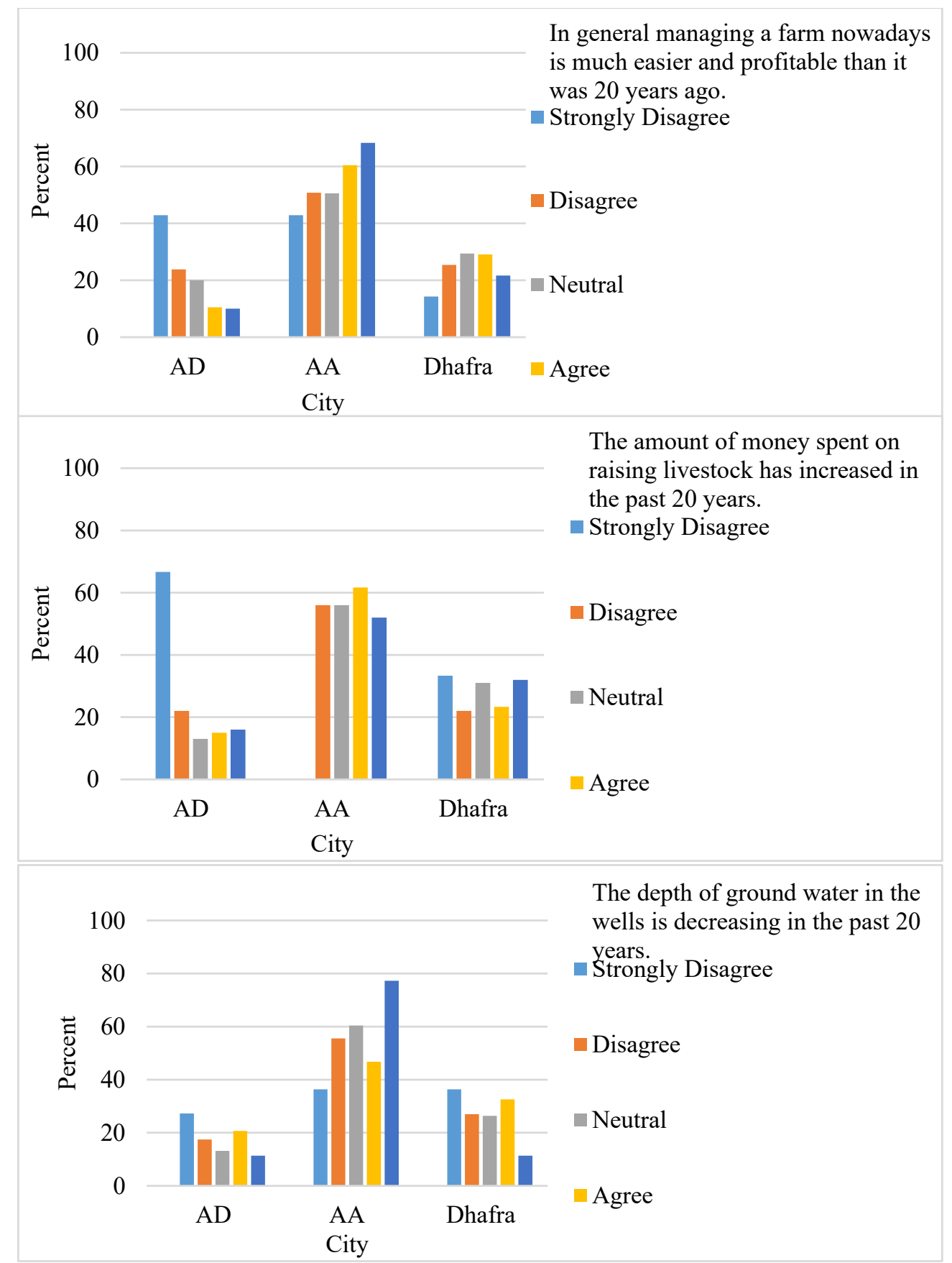

Fig. Cont.... 


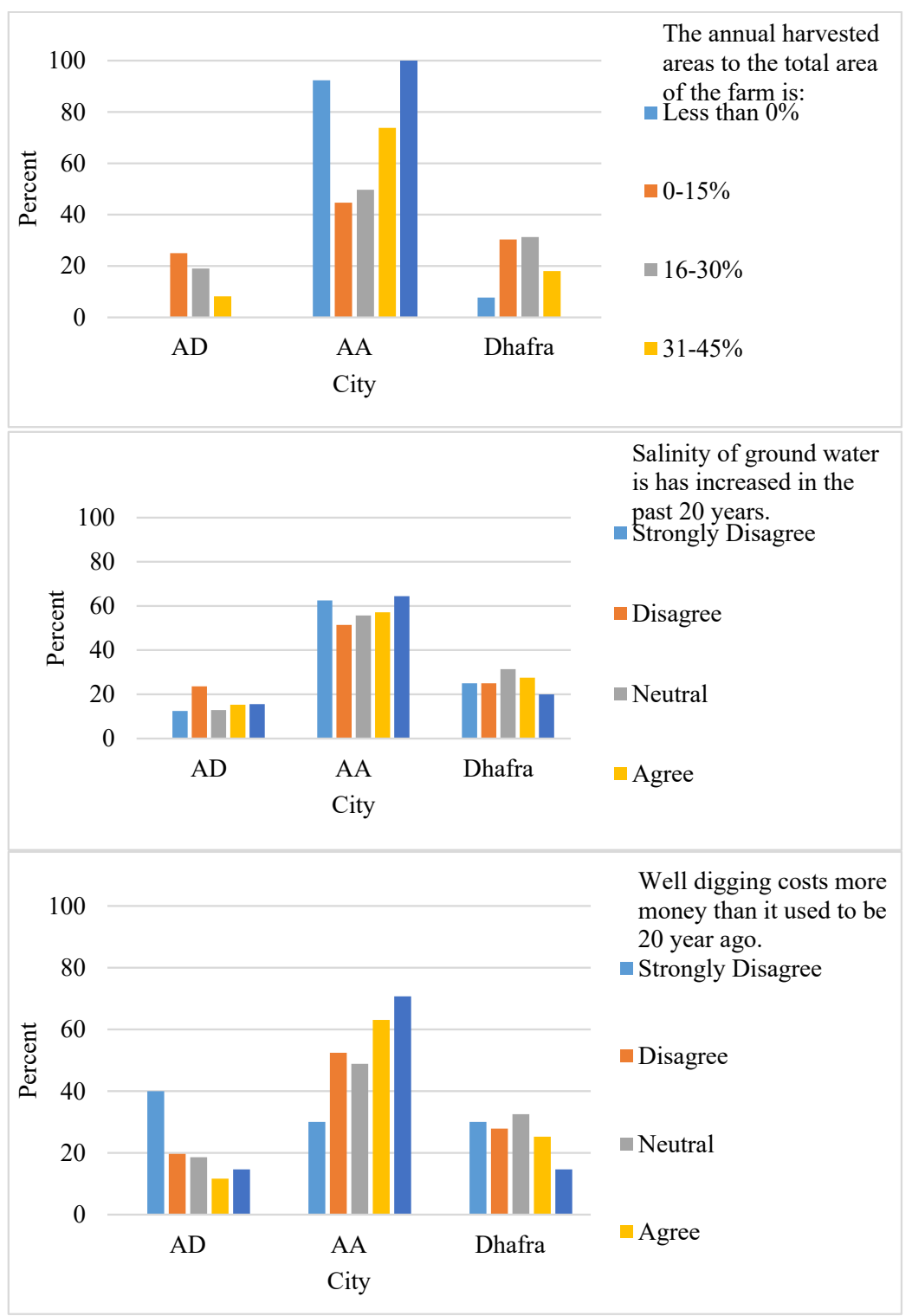

Fig. 4: Survey responses in different cities.

We analyzed the survey questions with each category's average for the survey variables. We excluded gender because there was only one female farmer respondent. The results showed that, for the production category, $39 \%$ of the farmers agreed more that production quality and quantity has increased in the past 20 years. In Al-Ain, $46 \%$ of the respondents remarked that their production had increased. The farm owners agreed more that their production increasing $(47 \%)$ in comparison to the workers. In regard to ages, approximately half (50\%) of the respondents aged between 20-30 and 51-60 years reported that their production is increasing (Fig. 4).
For the change in production over time category, we found that $41 \%$ of the farmers in Al-Ain, 30\% in Abu Dhabi, and $33 \%$ in AI Dhafrah agreed that there has been a change in production over time. A majority of the UAE nationals $(51 \%)$ agreed that there has been a change in production over time, with $42 \%$ of Arabs and $28 \%$ of Asians also agreeing with this statement. (Figs. 5 and 6). The farmers aged between 51-60 years agreed that there has been a change in production over time. Approximately $50 \%$ of the farm owners agreed that there has been a change in production, while the majority of the workers responded neutrally on this topic. 


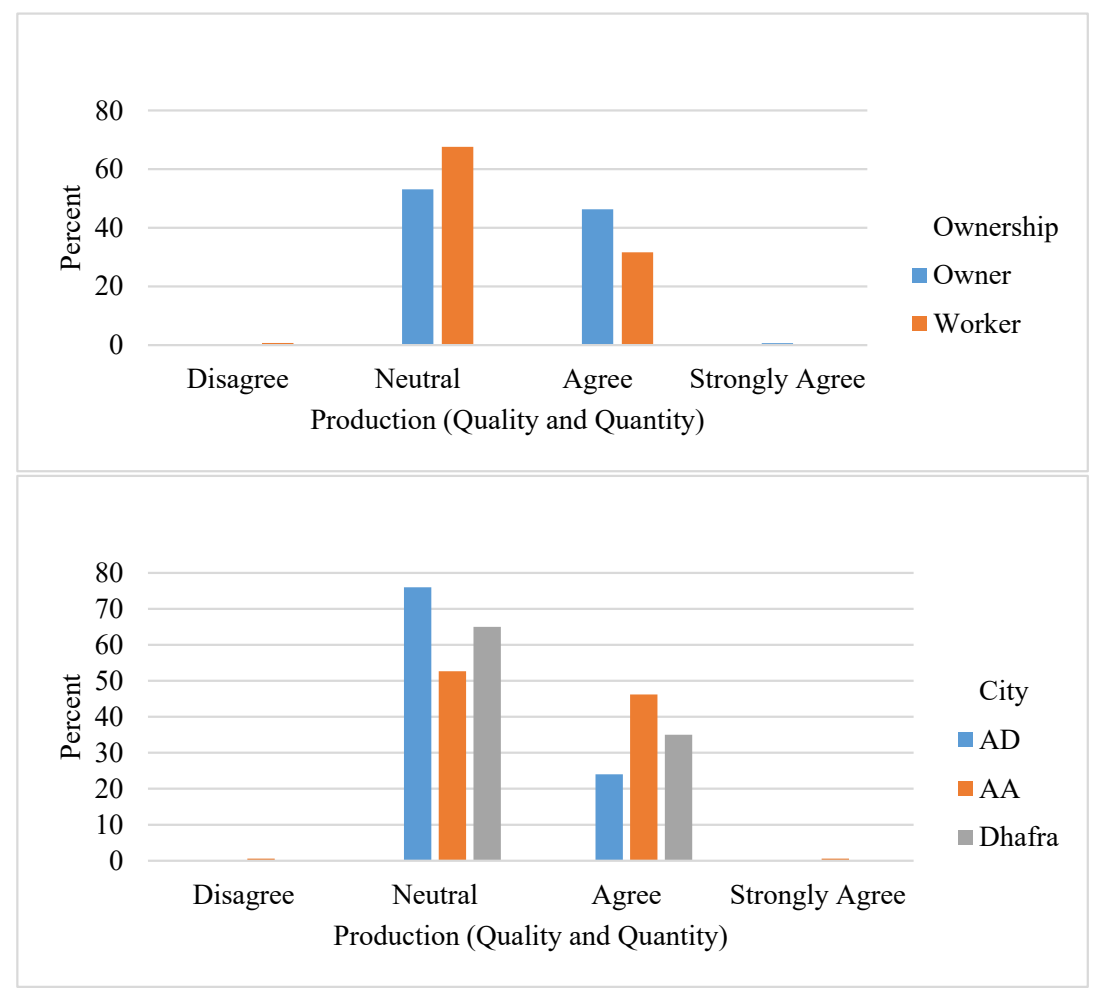

Fig. 5: Survey responses on production quality and quantity questions.

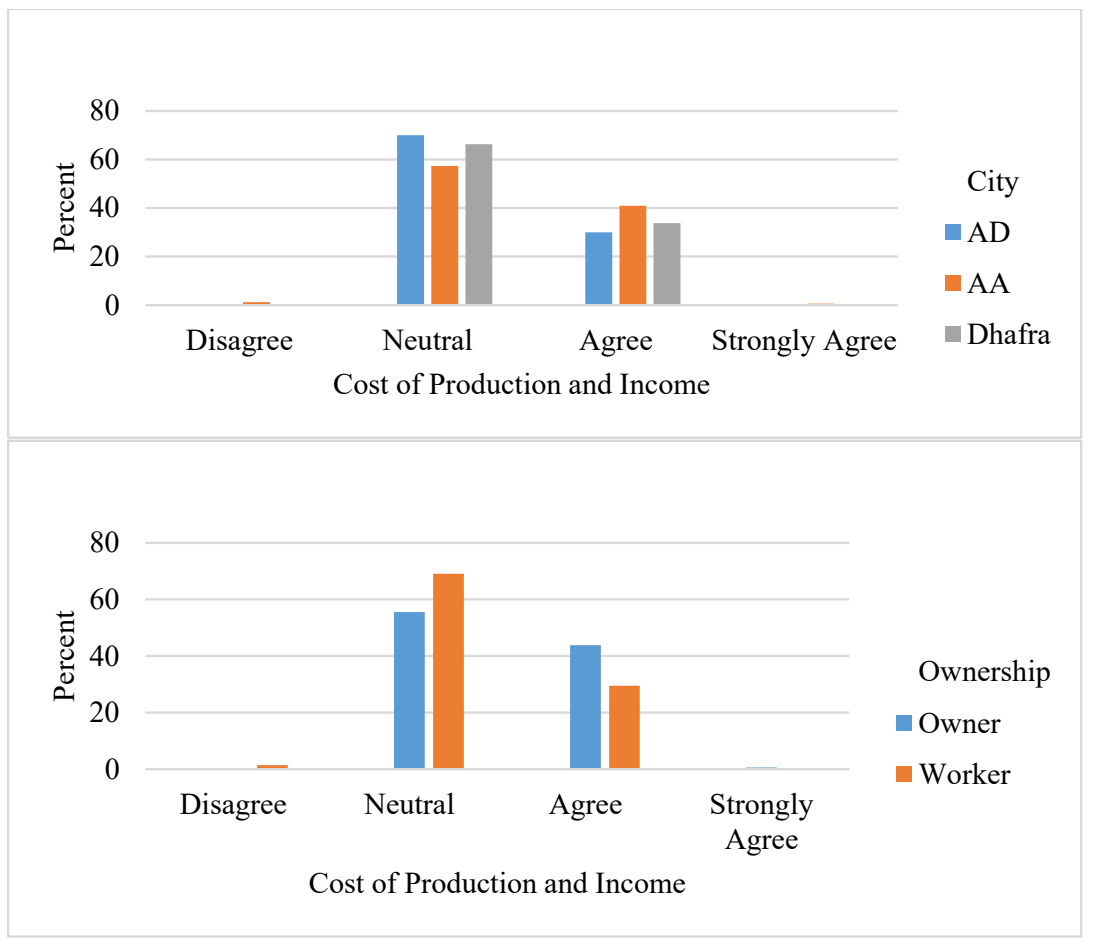

Fig. 6: Responses on the cost of production and income questions. 
For the cost of production and income category, both the owners and workers agreed that there has been a change in both production and income. However, more workers disagreed $(50 \%)$ than workers who agreed $(35 \%)$ with this statement. In Al-Ain, $40 \%$ of farmers agreed that there have been changes in both income and production costs, while only $34 \%$ and $30 \%$ of the farmers in Al Dhafra and Abu Dhabi agreed, respectively (Fig 7).

Survey responses on wells and groundwater questions are provided in Fig. 8. Farmers aged between 51-60 years agreed more compared to other group ages, that there have been changes in the groundwater level over the past 20 years. Approximately $32 \%$ of the workers disagreed that there has been a change in the groundwater quantity, while $18 \%$ of the owners agreed. The majority of the respondents were neutral in their responses to this set of questions. The farmers in Abu Dhabi disagreed that there has been a change in the groundwater quantity (26\%), and $20 \%$ of the AlDhafrah farmers also disagreed. In this case, the percentage of farmers who disagreed was equal to the percentage of farmers who agreed with the groundwater quantity statement (both 18\%) in the mentioned cities.
Given that the Likert-type data are ordinal, we used nonparametric techniques to analyze the data. We conducted a Mann-Whitney test to analyze the difference in scoring tendencies between two groups' demographic variables. Wealsoconducted a Kruskal-Wallis test to analyze the difference in the participants' scoring tendencies for the demographic variables of more than two groups. For gender and ownership, we used two variables (Mann Whitney Test), and we used $\mathrm{K}$ variables for nationality, city, and age (Kruskul-Wallis Test). The Asymptomatic Significance values are given in Table 3. Our data indicate that there is a significant difference $(\mathrm{P}<0.05)$ between nationality and age for question 8 (I plant vegetable crops in my farm). For question 11 (I sell all my produced crops in the market), there is a significant difference between ownership and nationality. There was also a significant difference between ownership and nationality for questions 12, 20, 28 and questions 31-38. For question 22 (the total amount of farm expenses has increased over the last 20 years), there is a significant difference between ownership and nationality and age.

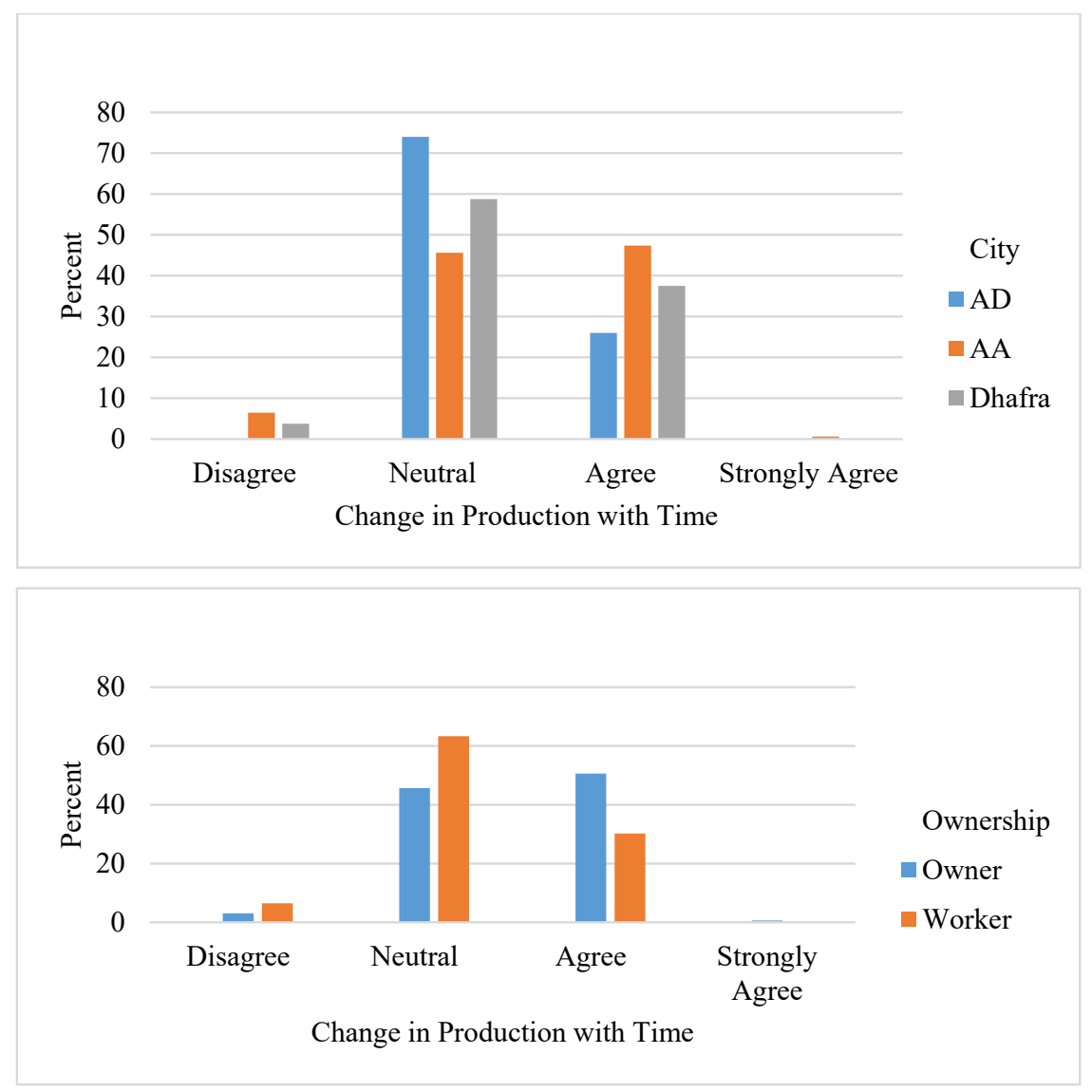

Fig. 7: Survey responses on change in production over time questions. 


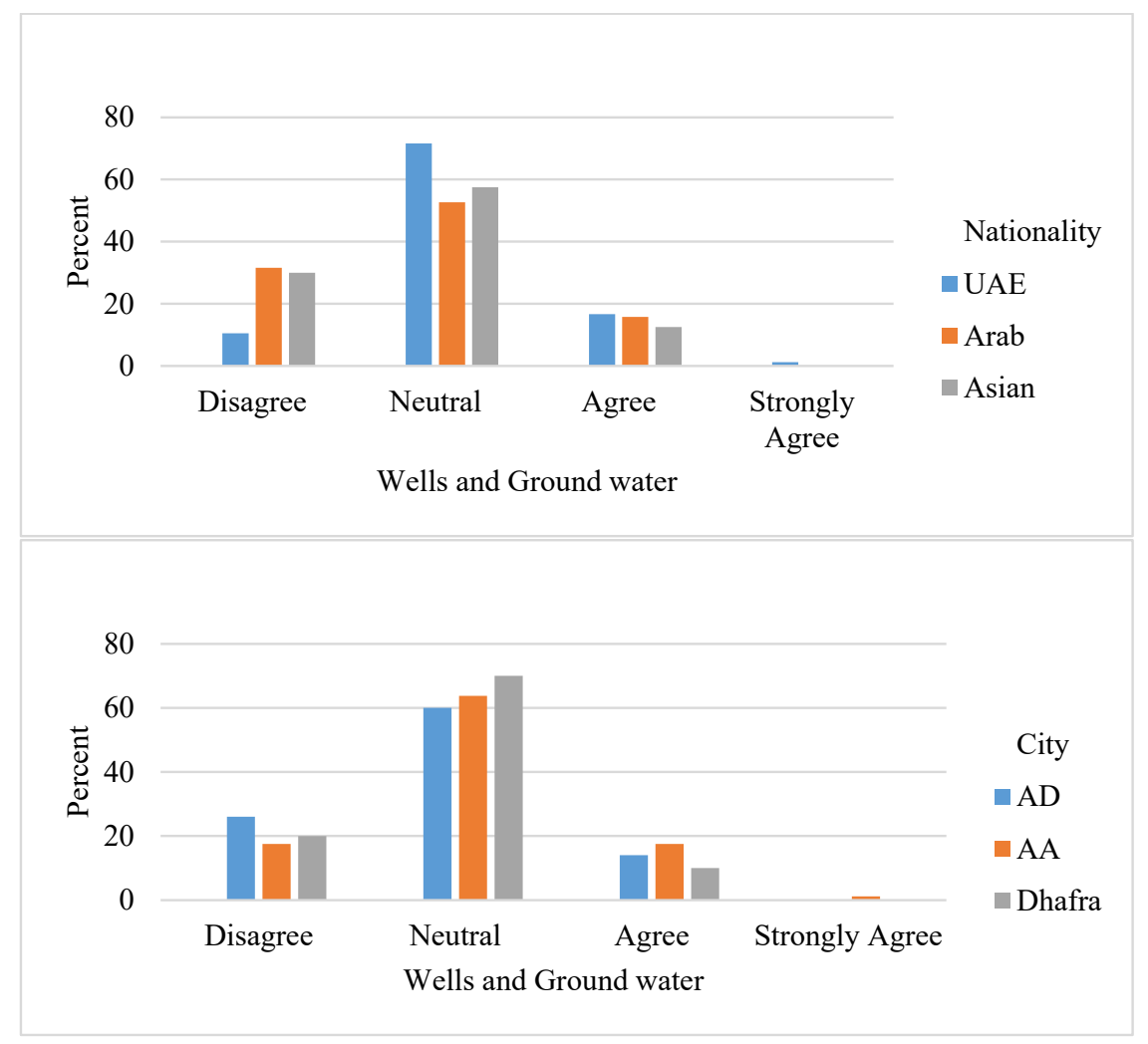

Fig. 8: Survey responses on wells and groundwater questions.

Table 3: Asymptomatic significance values for survey questions.

\begin{tabular}{|llllll|}
\hline Question & Gender & Ownership & Nationality & City & Age \\
\hline 1 & 0.284 & 0.912 & 0.542 & 0.234 & 0.050 \\
2 & 0.357 & $0.006^{*}$ & $0.024^{*}$ & 0.599 & $0.000^{*}$ \\
3 & 0.479 & $0.045^{*}$ & 0.091 & 0.531 & 0.903 \\
4 & 0.173 & 0.165 & 0.306 & 0.489 & $0.015^{*}$ \\
5 & 0.117 & 0.629 & 0.636 & 0.612 & $0.005^{*}$ \\
6 & 0.415 & 0.375 & 0.660 & 0.066 & 0.161 \\
7 & 0.952 & $0.043^{*}$ & 0.109 & 0.518 & 0.209 \\
8 & 0.988 & 0.343 & $0.029^{*}$ & 0.085 & $0.044 *$ \\
9 & 0.085 & 0.146 & 0.175 & $0.00 *$ & 0.135 \\
10 & 0.143 & $0.034^{*}$ & 0.089 & $0.00^{*}$ & 0.131 \\
11 & 0.607 & $0.012^{*}$ & $0.042^{*}$ & 0.611 & 0.783 \\
12 & 0.100 & $0.001^{*}$ & $0.002^{*}$ & 0.862 & 0.444 \\
13 & 0.105 & 0.298 & 0.238 & 0.617 & 0.347 \\
14 & 0.571 & 0.144 & 0.397 & 0.359 & 0.056 \\
15 & 0.440 & 0.379 & 0.414 & 0.787 & 0.444 \\
16 & 0.126 & 0.671 & 0.671 & $0.023^{*}$ & 0.944 \\
17 & 0.164 & 0.911 & 0.451 & 0.180 & 0.771 \\
18 & 0.145 & 0.056 & 0.061 & 0.661 & 0.974 \\
\hline
\end{tabular}

\begin{tabular}{|c|c|c|c|c|c|}
\hline Question & Gender & Ownership & Nationality & City & Age \\
\hline 19 & 0.653 & 0.208 & 0.171 & 0.594 & 0.653 \\
\hline 20 & 0.448 & $0.018^{*}$ & $0.02 *$ & 0.369 & 0.349 \\
\hline 21 & 0.191 & 0.254 & 0.183 & 0.697 & 0.682 \\
\hline 22 & 0.607 & $0.005^{*}$ & $0.031 *$ & 0.915 & $0.023^{*}$ \\
\hline 23 & 0.471 & 0.131 & 0.144 & 0.434 & 0.451 \\
\hline 24 & 0.188 & $0.023 *$ & 0.074 & $0.015^{*}$ & 0.109 \\
\hline 25 & 0.241 & $0.000^{*}$ & $0.001 *$ & 0.554 & $0.019 *$ \\
\hline 26 & 0.209 & 0.708 & 0.694 & $0.002 *$ & 0.963 \\
\hline 27 & 0.476 & 0.810 & 0.954 & $0.001 *$ & $0.033^{*}$ \\
\hline 28 & 0.288 & $0.047 *$ & $0.039^{*}$ & $0.000 *$ & 0.585 \\
\hline 29 & 0.932 & $0.000^{*}$ & $0.000^{*}$ & $0.000^{*}$ & 0.206 \\
\hline 30 & 0.179 & 0.109 & 0.232 & 0.083 & 0.138 \\
\hline 31 & 0.146 & $0.021 *$ & $0.046^{*}$ & 0.328 & 0.346 \\
\hline 32 & 0.144 & $0.008^{*}$ & $0.016^{*}$ & 0.256 & 0.652 \\
\hline 33 & 0.651 & $0.001 *$ & $0.002 *$ & $0.007 *$ & 0.608 \\
\hline 34 & 0.327 & $0.000^{*}$ & $0.000 *$ & 0.199 & 0.392 \\
\hline 35 & 1.000 & $0.001 *$ & $0.002 *$ & 0.029 & $0.042 *$ \\
\hline 36 & 0.302 & $0.001 *$ & $0.001 *$ & $0.009^{*}$ & 0.098 \\
\hline 37 & 0.304 & $0.001 *$ & $0.002 *$ & $0.001 *$ & 0.701 \\
\hline 38 & 0.400 & $0.000 *$ & $0.002 *$ & $0.024 *$ & 0.320 \\
\hline
\end{tabular}

*Sig. at 0.01 level 


\section{DISCUSSION}

It is known that climate change will not impact all farms equally (Claessens et al. 2012). While some farms will be greatly impacted by climate change, others will not be impacted at all. Our results indicated that approximately $68 \%$ of the respondents in Al-Ain agreed that managing a farm nowadays is much easier and more profitable than it was 20 years ago. In Al Dhafrah, 29\% of the respondents agreed with this statement, while the majority of the Abu Dhabi respondents disagreed. These results indicate that the farms in Al-Ain are not influenced by climate change, or, that climate change's influence is more manageable in Al-Ain than it is in Abu Dhabi (where the majority of the farmers were unable to easily manage their farms). Differing governmental policies do not factor in here, as both Al-Ain and Abu Dhabi are governed by the same regulations and codes. Besides, farmers in both Al-Ain and Abu-Dhabi receive similar services and aid amounts from the government.

Instead, climate-related factors may be the drivers of the farms' managing processes. Scanlon et al. (2005) reported that, in the next 50 years, the area of agricultural lands are going to increase by $20 \%$. This supports our results, which indicate that $80 \%$ of the Al-Ain farmers strongly agreed that their production has increased over the past 20 years. However, only $28 \%$ and $18 \%$ of the respondents in AI Dhafrah and Abu Dhabi City agreed, respectively. SCAD (2018) reported that the estimated number of livestock in 2017 was 613,841 in Abu Dhabi, 2,335,268 in Al-Ain, and 595,891 in Al Dhafrah. When questioned about whether the amount of money they spent raising livestock had increased over the past 20 years, the majority of Al-Ain respondents either disagreed or responded neutrally (more than 60\%), nearly $70 \%$ of respondents in Abu Dhabi disagreed, and 34\% of the respondents in $\mathrm{Al}$ Dhafrah disagreed. The farmers in the three cities of our study area are managing the livestock properly, and it is clear that they are not facing financial or other possible issues in raising them.

The total value of field crop production was 325,654 AED in Abu Dhabi Emirate, comprised of $74.8 \%$ in Al-Ain, $17.3 \%$ in $\mathrm{Al}$ Dhafrah, and $8.0 \%$ in Abu Dhabi City (SCAD 2018). More than $50 \%$ of the farm owners (UAE nationals) strongly agreed that their crop-selling income has increased over the past 20 years, while the majority of workers (Arabs and Asians) either disagreed or responded neutrally. The farm owners handle the financial matters related to their farms; the income flows directly to the owners' accounts, while the workers receive their salaries without knowledge of the farm's total profit. Mertz et al. (2009) found that farmers in agricultural countries have been able to develop their strategies for continuously managing the unpredictable climate, pest attacks, and changing policies.
Al-Ain, as the city of an oasis, is known for its agricultural and livestock production, as its people are highly experienced in farming and irrigating techniques and in managing the different cultivation tools. This might explain why the Al-Ain farmers had more positive responses than the respondents in Abu Dhabi and Al Dhafrah. For the production quality and quantity category, 50\% of the respondents aged between 5160 years reported that their production is increasing. These respondents likely provided better and more reliable answers, as they have had experience with farming over the last 20 years. For the change in production over time category, we found that $41 \%, 30 \%$, and $33 \%$ of the farmers in Al-Ain, Abu Dhabi, and Al Dhafrah, respectively, noted that production has changed over time. Al-Ain's higher positive percentage for this category is likely also explained by the same reasons listed above. The UAE nationals (51\%), Arabs (42\%), and Asians (28\%) also agreed that there has been a change in production over time. The farmers aged between 51-60 years also agreed that there has been a change in production over time. Approximately half $(50 \%)$ of the farm owners agreed that production has changed over time, while the majority of workers responded neutrally on this topic. In general, the workers tended to respond neutrally to the questions, which might have been because they were not aware of the issues or because they did not properly understand the questions (due to language differences [for the Asian respondents] or low educational levels [for the Asian or Arab respondents]).

For the cost of production and income category, both owners and workers agreed that income and production costs have changed; however, more workers disagreed (50\%) than agreed $(35 \%)$ with this statement. Approximately $40 \%$ of the farmers in Al-Ain, 34\% in AI Dhafra, and 30\% in Abu Dhabi agreed that income and production costs have changed. The expenses and incomes are both increasing, which has occurred in various businesses due to increases in oil prices, demand for goods, etc. The farm owners thus sell their crops and livestock at higher prices, which could subsequently translate into higher income. Although the total loans given to the farmers in the agricultural sector in Al-Ain was decreased to $166,000 \mathrm{AED}$, where it was $21,752,000 \mathrm{AED}$ in 2010 and to 147,000 AED in 2017 compared to 4,967,000 AED in Abu Dhabi and AlDhafrah in 2010 (SCAD 2018).

Many farms have been abandoned over the past 20 years due to the new policies and regulations, yet the farmers we surveyed are productive farmers. A study conducted on water consumption rates in the different KSA sectors found that modern irrigation (localized and sprinkler irrigation) covers about $66 \%$ of the total irrigated area in the KSA, with the remaining proportion (34\%) using surface irrigation (IMF, 2013). Our results showed that almost $60 \%$ of the farmers in Al-Ain use sprinklers for their irrigation systems, followed 
by the Aflaj and drip systems. The majority of Abu Dhabi farmers use drip irrigation systems (25\%), while $34 \%$ of the farmers in Al Dhafrah use the Aflaj system.

Many scientists have proposed that climate change might influence the physical characteristics of aquifers (Shah 2009). Our results indicated that farmers aged between 5160 years agreed more so than did younger farmers, that the groundwater quantities and quality have changed over the past 20 years. This result is important because this age range has the most experience with farming. The majority of the respondents provided neutral responses to this set of questions. It is unclear whether the respondents were not aware of the groundwater's status or if they did not understand the questions due to language differences or other factors. The farmers in Abu Dhabi (26\%) and AlDhafrah (20\%) disagreed that the groundwater levels had changed.

Alauddin \& Sarker (2014) found that the majority of farm households in Bangladesh had observed that both groundwater and surface water were less available during the summers than they used to be. While we did not focus on a specific season, Alauddin and Sarket's study applies to the study region, as the region is dry and hot for most of the year. Groundwater wells are the most important tools that farmers have used to survive droughts. Consequently, well digging tends to peak during drought years, and this is expected to continue and even increase with the amplified hydro-climatic variability (Shah 2009). Approximately $70 \%$ of the farmers in Al-Ain strongly agreed that well digging currently costs more money than it used to cost 20 years ago. In Abu Dhabi and Al Dhafrah, $16 \%$ and 24\% of the farmers agreed that the digging costs had increased, respectively. This cost increase could be due to increases in machinery costs and/or water depths.

\section{CONCLUSION}

Of our 301 respondents, $64 \%$ of the local farmers agreed that the total farm expenses had increased over the past 20 years. Also, the local farmers strongly agreed that their crop-selling income had also increased over the past 20 years. Approximately $32 \%$ of the farmers aged between 51-60 years agreed more compared to the younger groups, that the groundwater levels and quality had changed over the past 20 years. The farmers in Al-Ain agreed that the groundwater's salinity had increased over the past 20 years. Generally, $68 \%$ of the Al-Ain respondents reported that managing a farm nowadays is much easier than it was 20 years ago.

In addressing the research questions, it is possible to determine that there has been a change in agricultural and livestock production over the past 20 years and that this change varies (in both amount and nature) across the different regions of Abu Dhabi Emirate. We assumed that climate change has influenced agriculture and livestock production, and we built our survey on this assumption to assess how climate change has impacted farm production and groundwater characteristics. Climate change's negative influence was not indicated in our findings. The responses indicated that both agricultural and livestock production have recently increased. Also, the responses suggest that groundwater characteristics have not been influenced by climate change. We think that our findings open the door for future researchers to further explore the region in regard to climate change's influence on agricultural and livestock production through other factors including groundwater.

\section{ACKNOWLEDGMENTS}

The authors would like to acknowledge the Abu Dhabi Food Control Authority (ADFCA) and the graduate school at UAE University for funding this project.

\section{REFERENCES}

Al-Maamary, H.M., Kazem, H.A. and Chaichan, M.T. 2017. Climate change: The game changer in the gulf cooperation council region. Renewable and Sustainable Energy Reviews, 76: 555-576.

Al Shidi, H., Sulaiman, H. and Amoatey, P. 2016. Shifting to renewable energy to mitigate carbon emissions: Initiatives by the states of gulf cooperation council. Low Carbon Economy, 7: 123.

Alauddin, M. and Sarker, M.A.R. 2014. Climate change and farm-level adaptation decisions and strategies in drought-prone and groundwaterdepleted areas of Bangladesh: an empirical investigation. Ecological Economics, 106: 204-213.

Bruce, J.P., Lee, H. and Haites, E.F. 1996. Climate Change 1995: Economic and Social Dimensions of Climate Change.

Claessens, L., Antle, J., Stoorvogel, J., Valdivia, R., Thornton, P.K. and Herrero, M. 2012. A method for evaluating climate change adaptation strategies for small-scale farmers using survey, experimental and modeled data. Agricultural Systems, 111: 85-95.

Gerber, P., Vellinga, T., Opio, C., Henderson, B. and Steinfeld, H. 2010. Greenhouse gas emissions from the dairy sector: A life cycle assessment. Food and Agriculture Organization of the United Nations, Rome, Italy.

Houghton, J.T., Meiro Filho, L., Callander, B.A., Harris, N., Kattenburg, A. and Maskell, K. 1996. Climate change 1995: The science of climate change: Contribution of working group I to the second assessment report of the Intergovernmental Panel on Climate Change (Volume 2). Cambridge, UK, Cambridge University Press.

Ibrahim, S.B., Ayinde, I.A. and Arowolo, A.O. 2015. Analysis of arable crop farmers awareness to causes and effects of climate change in southwestern Nigeria.

International Journal of Social Economics, 42: 614-628.

IMF 2013. Economic prospects and policy challenges for the GCC Countries.

Technical Report. Report presented at the Annual Meeting of Ministers of Finance and Central Bank Governors, Saudi Arabia.

Kløve, B., Ala-Aho, P., Bertrand, G., Gurdak, J.J., Kupfersberger, H., Kværner, J., Muotka, T., Mykrä, H., Preda, E., Rossi, P. and Uvo, C.B. 2014. Climate change impacts on groundwater and dependent ecosystems. Journal of Hydrology, 518: 250-266. 
McGuire, A.D., Sitch, S., Clein, J.S., Dargaville, R., Esser, G., Foley, J., Heimann, M., Joos, F., Kaplan, J., Kicklighter, D.W. and Meier, R.A. 2001. Carbon balance of the terrestrial biosphere in the twentieth century: Analyses of $\mathrm{CO}_{2}$, climate and land use effects with four process-based ecosystem models. Global Biogeochemical Cycles, 15: 183-206.

Mertz, O., Mbow, C., Reenberg, A. and Diouf, A. 2009. Farmers perceptions of climate change and agricultural adaptation strategies in rural Sahel. Environmental Management, 43: 804-816.

MOE, 2007. Data sheet for the climate of UAE. Technical Report. Ministry of Economics, Metrology Department, Abu Dhabi.

Murad, A.A. 2010. An overview of conventional and non-conventional water resources in arid region: assessment and constrains of the United Arab Emirates (UAE). Journal of Water Resource and Protection, 2: 181.

Olesen, J.E. and Bindi, M. 2002. Consequences of climate change for European agricultural productivity, land use and policy. European Journal of Agronomy,

16: 239-262.

Parry, M., Rosenzweig, C., Iglesias, A., Fischer, G. and Livermore, M. 1999. Climate change and world food security: A new assessment. Global Environmental Change, 9: S51-S67.

Porter, J.R., Xie, L., Howden, M., Iqbal, M.M., Lobell, D., Travasso, M.I., Garrett, K., Lipper, L., McGrath, J., Aggarwal, P. and Hakala, K. 2014. Food Security and Food Production Systems. Methods, 7, pp.1-1.

Rizk, Z., Alsharhan, A. and Shindo, S. 1997. Evaluation of groundwater resources of United Arab Emirates. In: Proceedings of the 3rd Gulf Water Conference, pp. 95-122.

Rosenzweig, C. and Hillel, D. 2000. Soils and global climate change: Challenges and opportunities. Soil Science, 165: 47-56.

Sanderson, M.R. and Curtis, A.L. 2016. Culture, climate change and farmlevel groundwater management: An Australian case study. Journal of Hydrology, 536: 284-292.

SCAD 2018. Statistical Yearbook of Abu Dhabi 2018. Technical Report. Statistics Center, Abu Dhabi.

Scanlon, B.R., Reedy, R.C., Stonestrom, D.A., Prudic, D.E. and Dennehy, K.F. 2005. Impact of land use and land cover change on groundwater recharge and quality in the southwestern us. Global Change Biology, 11: $1577-1593$.

Shah, T. 2009. Climate change and groundwater: India's opportunities for mitigation and adaptation. Environmental Research Letters, 4: 035005.

Steinfeld, H., Gerber, P., Wassenaar, T., Castel, V., Rosales, M., Rosales, M. and de Haan, C. 2006. Livestock's long shadow: Environmental issues and options. Rome, Italy: United Nations Food and Agriculture Organization.

Stocker, T.F., Qin, D., Plattner, G.K., Tignor, M., Allen, S.K., Boschung, A., Nauels, Y., Xia, V., Bex, V. and Midgley, P. 2013. Summary for Policymakers. In: Climate Change 2013: The Physical Science Basis.

Watson, R.T., Zinyowera, M.C. and Moss, R.H. 1996. Climate Change 1995. Impacts, Adaptations and Mitigation of Climate Change: ScientificTechnical Analyses. Cambridge University Press. 